\title{
Przestrzenio-czas i czaso-kultura. Uwagi o komplementarności przestrzeni, kultury, czasu i krajobrazu
}

\begin{abstract}
1. Wstęp
Swoisty związek przyczynowo-skutkowy pomiędzy przestrzenią i kulturą wydaje się być czymś bezspornym. Kultura potrzebuje przestrzeni do swojego rozwoju; przestrzeń natomiast kształtuje rodzaj lokalnej kultury. Z kolei kultura stanowi tkankę krajobrazu kulturowego. W moim przekonaniu proponowana obecnie problematyka dyskusji wymaga jednak pewnego uzupełnienia. Chodzi o to, iż przyglądając się interakcjom pomiędzy przestrzenią i kulturą należy koniecznie uwzględnić twórczą rolę czasu. Czas \&\#8211; różnie definiowany, postrzegany, przeżywany itp. \&\#8211; pełni rolę modyfikatora tak w przypadku przestrzeni, kultury jak i krajobrazu.

Teza główna niniejszego wywodu to stwierdzenie, iż nie można osobno rozpatrywać przestrzeni, kultury bądź czasu. W rzeczywistości pomiędzy wzmiankowanymi elementami zachodzi zjawisko komplementarności, w efekcie którego mamy do czynienia z przestrzenio-czasem i czaso-kulturą. Oba wzmiankowane elementu stanowią przy tym składowe krajobrazu kulturowego. Moją tezę zdają się uzasadniać analizy poczynione przez Edwarda T. Halla. Jego koncepcje przestrzeni, czasu i kultury staną się jednym z głównych wątków niniejszego opracowania. Ich dopełnieniem będzie próba aplikacji Ruperta Sheldrake\&\#8217;a idei pola morficznego i morficznego rezonansu do problemu równoczesnej ewolucyjności i stabilności krajobrazu kulturowego.
\end{abstract}

\section{Problematyka przestrzeni}

Anonsowana kwestia istnienia przestrzenio-czasu wymaga przynajmniej skrótowego przestawienia czym jest przestrzeń i czas. W miarę precyzyjne uchwycenie obu rzeczywistości pozwoli lepiej zrozumieć wzajemne interakcje. 


\subsection{Metodologiczne aspekty analizy przestrzeni}

Pojęcie przestrzeni (a także czasu \&\#8211; o którym będzie mowa później) jest pojęciem nieostrym. Nie można w sposób prosty odpowiedzieć na pytanie: czym jest przestrzeń? Jest tak ponieważ w przypadku przestrzeni (oraz czasu) trudno podać jednoznaczne cechy konstytuujące przestrzeń. Jak zauważa Stanisław Mazierski człowiek nie tworzy przestrzeni. Człowiek \&\#8222; zastaje\&\#8221; przestrzeń. Musi wobec niej zająć jakąś postawę badawczą po to, aby ją określić i zdefiniować. Ponieważ wyniki badawcze nie prowadzą do niezawodnych rezultatów człowiek usiłuje uzupełnić luki różnymi koncepcjami przestrzeni \&\#8211; mniej lub bardziej odpowiadającymi rzeczywistości badanej [Mazierski 1962:74].

Analizując zagadnienie przestrzeni zaznaczyć trzeba, iż istnieją dwa rodzaje poznania: zmysłowe i umysłowe. Wobec tego czymś innym jest np. wyobrażenie, doświadczenie przestrzeni a czymś innym pojęcie przestrzeni. Przestrzeń jako taka może być różna. Ze względu na rodzaj poznania wyróżniamy zatem następujące rodzaje przestrzeni: przestrzeń oglądową, konceptualną, matematyczną i fizyczną.

Przestrzeń oglądowa \&\#8211; obszar, do poznania którego dochodzi się na podstawie wrażeń dotykowych, wzrokowych, mięśniowych itp. Poprzez doświadczenie dotykowe czy wzrokowe mamy wyobrażenie bryłowatości, trójwymiarowości \&\#8211; przestrzenności. W pierwszym rzędzie, cecha \&\#8222; oglądowości\&\#8221; przysługuje ciałom materialnym. Dopiero wtórnie oglądowość dotyczy przestrzeni [Mazierski 1962:75n].

Przestrzeń konceptualna, wyimaginowana \&\#8211; to rezultat abstrakcji zastosowanej do ciał materialnych [Mazierski 1972:120]. Wrażenia zmysłowe informują nas, że przedmioty materialne są rozciągłe czyli, że części przedmiotów znajdują się obok siebie. W naszej analizie wydzielamy samą rozciągłość \&\#8211; abstrahujemy ją od innych właściwości ciał materialnych. Tak wyabstrahowaną rozciągłość ujmujemy w trzech wymiarach przedłużając każdy z wymiarów bez ograniczeń, w różnych kierunkach. W efekcie otrzymujemy przestrzeń o cechach absolutnych - byt rozciągly, pojemnik dla ciał, konieczny warunek istnienia przedmiotów materialnych. Jest niezależna od czasu i ciał w niej się znajdujących - może istnieć samodzielnie nawet bez ciał.

Przestrzeń matematyczna - to wytwór ludzkiego umysłu, twór abstrakcyjny [Jędrzejczyk 2001: 87]. Jest ona przedstawiona w języku matematyki. Za podstawę przestrzeni matematycznej przyjmuje się układ aksjomatów. Z tego względu pojęcia stosowane $w$ ramach przestrzeni matematycznej posiadają taki sens, jaki nadają im aksjomaty. Przestrzeń matematyczna jest niezależna od doświadczenia. Nie potrzebuję odwoływać się do rzeczywistości fizycznej, aby zweryfikować swoje tezy. Jej elementy (punkt, prosta, płaszczyzna itp.) nie mają jednoznacznych 
odpowiedników w rzeczywistości fizycznej. Przestrzeń matematyczna to geometria. Wszystkie znane nam geometrie (np. Euklidesa, Riemanna, ŁobaszewskiegoBolyai\&\#8217;a) możemy zatem uważać za przestrzenie matematyczne a ściśle za teorie takich przestrzeni. Ponieważ teoretycznie istnieje nieskończona liczba geometrii - tym samym nieskończona liczba możliwych teorii przestrzeni matematycznych [Wciórka 1993:44-47].

Przestrzeń fizyczna \&\#8211; przedmiot badań fizyki. Coś realnego, swoista \&\#8222;scena\&\#8221; na której rozgrywają się zdarzenia fizyczne [Heller, Lubański, Ślaga 1997:180-183]. Jest ona ukonstytuowana przez materię. W zależności jaką przyjmiemy koncepcję budowy materii (np. korpuskularno-falowa teoria budowy materii, teoria super strun itp.) takie właściwości posiadać będzie przestrzeń [Hawking, Penrose 1996; Liddle 2000:48-54] ]. Biorąc za punkt wyjścia korpuskularno-falową teorię budowy materii przestrzeń fizyczną będą konstytuować cząstki (agregaty materii) \&\#8211; jak np. protony, neutrony, mezony, neutrina itp. \&\#8211; oraz pola takie jak: pole elektromagnetyczne, pole mezonowe, neutrinowe itp.

Nieco inny pogląd na przestrzeń fizyczną prezentuje Albert Einstein. Jego zdaniem wszechświat zbudowany jest z punktów \&\#8211; zdarzeń, które zachodzą w określonych momentach czasu, \&\#8222; miejscach przestrzeni\&\#8221;. Charakterystyka punktowych zdarzeń następuje poprzez współrzędne położenia i czasu. Punktowe zdarzenia tworzą właściwą przestrzeń fizyczną \&\#8211; czasoprzestrzeń [Einstein: 1958:39]. Dla oznaczenia położenia punktu w przestrzeni fizycznej posługujemy się różnymi układami współrzędnych \&\#8211; np. trójwymiarowym kartezjańskim układem współrzędnych. Pytanie o położenie danego punktu ma sens jedynie wtedy, gdy weźmiemy pod uwag̨ określony układ odniesienia. Ten ostatni jest niczym innym jak jakimś ciałem, względem którego rozpatrujemy zjawisko.

Dyskutując o przestrzeni i kulturze poruszamy się w obszarze, który umownie możemy nazwać przestrzenią kulturową. Stanowi ona rodzaj przestrzeni społecznej (egzystencjalnej). To w jej obszarze jednostka ludzka doświadcza swojego bycia. Jak zauważa Christian Norberg-Schulz [2000:34] przestrzeń taka jest jednym $z$ aspektów egzystencji człowieka. Wydaje się, iż jej istnienie odkrywamy tak w przestrzeni oglądowej, konceptualnej jak i fizycznej. Tworzona jest przez nasze zmysły, intelekt, behawior i otaczające nas środowisko fizyczno-biologiczne. Rodzi się zatem podstawowa \&\#8211; moim zdaniem \&\#8211; uwaga metodologiczna. Badacz analizujący zjawiska, procesy itp. zachodzące w przestrzeni kulturowej musi być szczególnie wyczulony na sytuacje \&\#8222;miejsca\&\#8221;, w którym się znajduje. Czyha na niego bowiem pułapka pomieszania poziomów poznawczych \&\#8211; opisywania czegoś choćby z poziomu oglądowego (zmysłowego) poprzez np. język obowiązujący w przestrzeni konceptualnej itp.

Przedstawione dotychczas koncepcje przestrzeni akcentują aspekt teoriopoznawczy (epistemologiczny) analiz. Równie ważne zdaje się być spojrzenie na 
przestrzeń od strony ludzkich działań i zachowań. Kulturowe ujęcie przestrzeni akcentuje jej wymiar antropologiczny [Jędrzejczyk 2001: 81-94] czy wręcz egzystencjalny [Norberg-Schulz 2000:17-35]. Moim zdaniem przestrzeń kulturową można postrzegać jako sferę relacji społecznych, interakcji i sprzężeń zwrotnych między człowiekiem, jego zmysłami, intelektem, behawiorem a przestrzenią fizyczną. Jeśli tak jest $\mathrm{w}$ istocie natrafiamy $\mathrm{w}$ tym momencie na swoisty paradoks (ujawnia się on także przy dyskusji o przestrzeni społecznej) [Łapiński 2002:34-35] mianowicie, iż przestrzeń kulturowa to jednocześnie i metafora i fragment konkretnej przestrzeni fizycznej. Sfera międzyludzkiego, społecznego dyskursu \&\#8211; ścierania się poglądów, postaw, wizji świata itp. \&\#8211; a także wydzielone miejsce publiczne, przestrzeń architektoniczna [Norberg-Schulz 2000:37-39], pełne symboli, charakterystycznych budowli i innych desygnatów kulturowych [Krier 2001:111]. W moim przekonaniu zachodzi przy tym analogia pomiędzy kulturą a życiem \&\#8211; jak życie biologiczne wymaga dla swojego rozwoju odpowiedniego środowiska naturalnego tak również kultura domaga się tego samego. W takiej perspektywie przestrzeń jawi się jako środowisko kultury \&\#8211; środowisko nie tylko w aspekcie biologicznym czy fizycznym (przestrzeń fizyczna) lecz również relacyjnym. Wymóg bogactwa interakcji (interróżnorodność) stanowi przy tym gwarancję rozwoju kultury. Śmiem twierdzić zatem, iż działania odpowiednich gremiów decyzyjnych zmierzające do ochrony poziomu interróżnorodności stanowić będą jeden $\mathrm{z}$ ważniejszych sposobów zachowania kultury lokalnej.

\subsection{Edwarda T. Halla przestrzeń jako forma komunikacji kulturowej}

Wydaje się, iż aspekt relacyjności w postrzeganiu przestrzeni kulturowej podkreśla koncepcja przestrzeni prezentowana przez Edwarda T. Halla. Dla cytowanego autora przestrzeń jest sposobem komunikacji kulturowej. Twierdząc tak odwołuje się on do poglądów Franza Boasa o tym, iż komunikacja stanowi nie tylko rdzeń kultury lecz i samego życia [Hall 2001a: 9]. Zdarzenia mające miejsce w przestrzeni rozchodzą się po niej jak kręgi po wodzie. Recepcja zdarzeń może dokonywać się na różne sposoby, na różnych dystansach i z różną intensywnością. Stąd według Halla należy mówić o interakcjach zachodzących w przestrzeni wzrokowej, słuchowej, węchowej, termicznej, dotykowej, wizualnej [Hall 2001a :59-100]. W każdym wzorcu kultury (np. europejskiej, arabskiej, japońskiej itp.) impulsy pochodzące $\mathrm{z}$ tych przestrzeni niosą innego rodzaju komunikat, który w zależności od rodzaju dystansu (dystans intymny, osobniczy, społeczny, publiczny) [Hall 2001a:145-162] tworzyć będzie inny model strukturalny przestrzeni (przestrzeń trwała, pół trwała, nieformalna) [Hall 2001a:131-144].

Zgłębienie specyfiki przestrzeni tworzonej przez daną kulturę jest w moim przekonaniu poznaniem ważnego klucza do zrozumienia danej kultury. Badacz 
musi się wręcz nauczyć przestrzeni grupy etnicznej. Dzieje się tak ponieważ zdaniem Halla człowiek wyraża siebie poprzez przestrzeń a z kolei przestrzeń mówi zarówno o tymże człowieku jak i kręgu kulturowym, do którego przynależy [Hall 1987:161].

\subsection{Metodologiczne aspekty analizy czasu}

Podobnie jak w przypadku przestrzeni, natura czasu, racja jego istnienia itp. są czymś nie w pełni poznanym zarówno dla fizyka jak i dla filozofa. Stąd też w przekonaniu Ludwika Wciórki analizując zagadnienie czasu badacz od samego początku napotyka na dwa odmienne jego ujęcia. a). Antropologiczne ujęcie czasu \&\#8211; czlowiek przeżywając swoje dzieje (swoje bycie) postrzega czas jako specyficzny wymiar własnej egzystencji. Czas tworzy moją egzystencję ponieważ \&\#8211; jak twierdzi Wciórka \&\#8211; jawi się jako \&\#8222;zróżnicowane jakościowo, odmienne dla każdego człowieka, nieprzestrzenne miejsce zdarzeń\&\#8221; [Wciórka: 1993:51]. b). Filozoficzne ujęcie czasu \&\#8211; czas ujmowany jest jako coś zewnętrznego w stosunku do ludzkiej egzystencji, coś zobiektywizowanego i abstrakcyjnego.

Z kolei z metodologicznego punktu widzenia \&\#8211; zdaniem Mazierskiego \&\#8211; w zagadnieniu czasu należy nadto odróżnić trzy aspekty: a). Ontologiczny - chodzi o sposób istnienia czasu; warunki jakie muszą zostać spełnione, aby zaistniał czas.

b). Psychologiczny - zwrócenie uwagi na przeżycie czasu. Inne jest przeżycie czasu a inne przeżycie ruchu.

c). Epistemologiczny (metodologiczny) - analizujemy w jaki sposób tworzymy pojęcie czasu i jak go określamy [Mazierski 1972:144].

Ogólnie mówiąc fizykalne ujęcie czasu ukazuje go jako dodatkowy wymiar (czwarty, obok trzech wymiarów przestrzennych) przy analizie zjawisk fizycznych. Z kolei na płaszczyźnie filozoficznej czas nie jest nam dany w taki sam sposób jak zjawisko lub rzecz bezpośrednio poznawalna zmysłami. Dopiero analizując ruch (zmianę) można wyodrębnić realność czasu w stosunku do innych czynników oraz wskazać na warunki pod jakimi jest możliwe jego istnienie. Wydaje się zatem być celowe wskazanie na choćby przykładowe (Platon, Arystoteles, Kant, Carrel) filozoficzne koncepcje czasu.

Zadniem Hellera [1986:9] odkrywcą istnienia czasu jest Platon. Problem czasu u Platona pojawia się jako element dyskusji o relacjach zachodzących pomię$\mathrm{dzy}$ istniejącym, stwarzanym przez Demuirga, światem fizycznym a światem idei (fizyki, matematyki). Idee są niezmienne, bytują w wieczności i stanowią wzorzec dla tworzenia realnego, zmiennego kosmosu. Problem w tym, że to co już istnieje w wieczności nie może jednocześnie się stawać. Demiurg rozwiązuje anonsowaną trudność. Tworzy równocześnie sprzęgnięte ze sobą dwa obrazy świata: 
pierwszy \&\#8211; wiekuisty, niezmienny obraz wieczności oraz drugi \&\#8211; poruszający się według liczby, ruchomy obraz tej samej wieczności. Ten drugi dla Platona jest czasem. W takiej perspektywie badawczej platoński czas to ruchomy obraz wieczności, trwający w jedności, ale poruszający się według liczby [Heller 1986:10]. Taki czas odznacza się jednością choć ma strukturę okręgu. Historia świata to bowiem nieustanny cykl wiecznych powrotów do momentu początkowego zorganizowania Kosmosu.

Arystoteles na podstawie przeprowadzonych przez siebie analiz postrzegał czas jako coś umiarkowanie realistycznego. W IV księdze Fizyki definiuje czas w sposób następujący: \&\#8222; czas jest [...] ilością ruchu ze względu na \&\#8222; przed\&\#8221; i \&\#8222; po\&\#8221;\&\#8221; [Arystoteles 1968:134]; \&\#8222; Czas jest miarą ruchu oraz miarą stanu ruchu [Arystoteles 1968:139]; \&\#8222;[...] czas jest miarą ruchu, wobec tego będzie pośrednio miarą spoczynku\&\#8221; [Arystoteles 1968:140]. Innymi słowy \& $\# 8222$; czas jest to miara (liczba) zmiany (pojętej jako pewien porządek) wyrażona przy pomocy przysłówków „wcześniej” i „później” [...]. Czas jest miarą zmiany (ruchu) i spoczynku” [za: Mazierski 1972:149]. Definicja ta ma charakter matematyczny \&\#8211; akcentuje się w niej liczenie zmian, czyli ruchów.

Immanuela Kanta teoria czasu wynika z ogólnych założeń jego systemu filozoficznego [Mazierski 1972:155-157]. Dla cytowanego autora czas jest kategorią podmiotową zmysłowości. Nie jest pojęciem empirycznym \&\#8211; nie wyprowadza się go z jakiegokolwiek doświadczenia [Kant 1957:107]. Czas jest koniecznym wyobrażeniem a priori, które warunkuje postrzeganie zjawisk [Kant 1957:114]. Zanim przystąpimy do poznania danych oglądowych, musimy wcześniej posiadać kategorie czasu. Umożliwia nam ona poznanie następstwa czasowego (lub równoczesności) zjawisk. Dla Kanta czas jest czystą formą zmysłowości naocznej. \&\#8222; Sam w sobie\&\#8221; jest niczym. O tyle jest realny empirycznie o ile związany jest $\mathrm{z}$ człowiekiem $w$ momencie gdy ten dokonuje procesu poznawania.

Aleksy Carrel zwraca uwagę na istnienie czasu wewnętrznego i zewnętrznego. Swoimi przemyśleniami zdaje się być kontynuatorem analiz poczynionych wcześniej przez Suareza. Carrel koncentruje się na idei czasu wewnętrznego. Za podstawę rozróżnień przyjmuje procesy: fizjologiczne, psychiczne i duchowe. Dla Carrela czas nie ma własnego bytu - jest sposobem istnienia przedmiotu [Mazierski 1972:153-155]. Każda istniejąca rzecz posiada bowiem swój ruch wewnętrzny \&\#8211; następstwo stanów, własny rytm itp. Carrelowski czas wewnętrzny to ruch wewnętrzny (np. fizjologiczny) jaki dokonuje się w każdym przedmiocie \&\#8211; następstwo stanów; to wyraz zmian ciała i jego aktywność w biegu życia; to wreszcie następstwo nieprzerwanych stanów strukturalnych, fizjologicznych, psychicznych itp. Stosowany powszechnie czas zewnętrzny (słoneczny, astronomiczny) nie jest miernikiem odpowiednim dla czasu wewnętrznego \&\#8211; procesów fizjolo- 
gicznych i psychicznych \&\#8211; mają one swój odrębny wewnętrzny czas [Carrel: 137-139]. Jedynie z braku innych jednostek jak dni, lata, itp. stosuje się je (ze zwykłej wygody) do pomiarów czasu wewnętrznego.

\subsection{Edwarda T. Halla czas - modyfikator przestrzeni}

Filozoficzne spojrzenie na czas, który ukazywał się jako \&\#8222;nieprzestrzenne miejsce zdarzeń\&\#8221; [Wciórka 1993:51] zostaje dopełnione wysuwaną przez Halla koncepcją czasu jako modyfikatora przestrzeni kulturowej. $\mathrm{Z}$ metodologicznego punktu widzenia nie można postrzegać wspomnianej koncepcji czasu jako elementu wpływającego na kształt przestrzeni fizycznej i tym samym tworzącego einsteinowską czasoprzestrzeń. Takie spojrzenie jest typowe dla fizyki relatywistycznej i dotyczy innego porządku poznawczego. Chodzi nam raczej o organizację przestrzeni, w ramach której jednostka ludzka przeżywa swoje bycie [Norberg-Schulz 2000:27].

Według Halla modyfikacja przestrzeni przez czas polega na tym, iż czas będąc \&\#8222; zbitką koncepcji, wydarzeń i rytmów \&\#8221; [Hall 1999:19] określa moment pojawiania się wydarzenia. Czas narzucając człowiekowi kolejność przeżywania zdarzeń (np. zmian pór roku, cykle celebracji świąt itp.) pośrednio narzuca także sposób ich realizacji. Przestrzeń i czas stają się czymś nierozdzielnym oraz wzajemnie warunkującym. Każde zdarzenie dokonuje się w przestrzeni i w jakimś wyraźnym momencie czasu (sakralnego, świeckiego, metafizycznego itp.). Pojawia się zatem przestrzenio-czas jako środek wglądu w kulturę [Hall 1999:12]. W ujęciu antropologicznym jest on także kreatorem różnych rodzajów przestrzeni \&\#8211; środowisk dla wielu rodzajów odrębnych kultur.

\section{Kultura a krajobraz kulturowy}

Anonsowana kwestia istnienia czaso-kultury wymaga obecnie zwrócenia uwagi na zjawisko kultury i interakcje zachodzące pomiędzy: wspomnianą kulturą, czasem, przestrzenią i krajobrazem kulturowym. Ich bezpośrednią konsekwencją powinno być zjawisko ewolucji krajobrazu kulturowego. Analizy swoje skoncentrujemy na tezach Edwarda Halla oraz sugestiach wysuwanych przez Ruperta Sheldrake\&\#8217; a. W moim przekonaniu pozwoli to nam uchwycić komplementarność czasu, przestrzeni, kultury i krajobrazu.

\subsection{Kultura jako forma komunikacji międzyludzkiej}

Encyklopedyczna definicja kultury stwierdza iż kultura to \&\#8222;ogół zasad, reguł i sposobów ludzkiego działania, wytworów ludzkiej pracy oraz twórczości stanowiący zbiorowy dorobek społeczeństw ludzkich, powstający na gruncie swo- 
istych biologicznych i społecznych cech człowieka i warunków jego bytu, a rozwijający się i przekształcający w procesie historycznym; również określony etap historycznego procesu rozwoju społeczeństw, wyrażający się stopniem opanowania sił przyrody, osiągniętym stanem wiedzy i twórczości artystycznej oraz formami współżycia społecznego [...]\&\#8221; [Encyklopedia... 1984:649]. Edward T. Hall proponuje nieco inne ujęcie kultury. Dla niego kultura jest formą komunikacji międzyludzkiej [Hall 1987:180]. Komunikacja ta składa się z trzech składników: diakrytów, zbiorów i wzorców. Jak zauważa Płachecki diakryty to podstawowe jednostki, kwanty (fony) kultury [Płachecki 1987:8-9]. Coś co pozwala rozróżnić zdarzenia kulturowe. Zbiory to konglomeraty diakrytów. W kulturze stanowią odpowiednik słów \&\#8211; konglomeratów dźwięków. Wzorce z kolei to konglomeraty zbiorów. Dla kultury wzorzec odpowiada językowemu zdaniu \&\#8211; konglomeratowi słów. Diakryty tworzą zbiory, zbiory budują wzorce, wzorce natomiast kojarząc się ze sobą organizują sieć lokalnych interakcji. Te ostatnie koncentrują się na jednej z trzech form ludzkich działań (zachowań): działaniach \&\#8222; formalnych \&\#8221; \&\#8222; nieformalnych\&\#8221; bądź \&\#8222; technicznych\&\#8221;. Dla naszych analiz najbardziej interesujące wydają się być zachowania \&\#8222; formalne\&\#8221;. Stanowią one wzorzec kultury opatrzony sankcją tradycji \&\#8211; tradycyjne, zrytualizowane.

W rozumieniu Halla koncepcja tak pojętej kultury jest po części lingwistyczna choć w dużej mierze odnosi się do ludzkich zachowań. Jego stwierdzenie \&\#8222;kultura jest komunikacją\&\#8221; Płachecki proponuje rozumieć w znaczeniu \&\#8222;kultura jest przekazem\&\#8221;; przekazem sekwencji zachowań, interakcji, zdarzeń itp. Kultura to podświadomie aplikowana technologia kontaktów z innymi [Płachecki 1987:14-15]. Dopowiadając do ostatniego stwierdzenia należy dodać, iż w moim przekonaniu kultura to, dziedziczona z pokolenia na pokolenie, zbiorowa \&\#8222;pamięć\&\#8221; społeczności ludzkiej. Kultura to także a-materialny, ale konstytutywny, składnik krajobrazu kulturowego. Przemiany dokonujące się w obszarze kultury istotnie determinują materialną, obiektywną, warstwę krajobrazu kulturowego. Innymi słowy: ewolucja kultury wyznacza kierunki przemian krajobrazu kulturowego. Problemem do rozstrzygnięcia pozostaje kwestia dlaczego tak się dzieje? Jest to w istocie próba uchwycenia istoty krajobrazu kulturowego.

Zdaniem Halla istnieją trzy główne poziomy funkcjonowania kultury rozumianej jako technologia kontaktów z innymi:

a. Poziom świadomy, techniczny. Decydujące znaczenie ma na nim język \&\#8211; słowa i specyficzne symbole, poprzez które przekazywane są innym komunikaty kulturowe.

b. Poziom prywatny. Strefa również dominacji języka ale ujawniająca swoje oblicze tylko wybranym osobom. 
c. Poziom nieświadomy \&\#8211; tzw. poziom prymarny kultury. W tym obszarze język pełni rolę drugorzędną w komunikacji kulturowej [Hall 1999:14].

Dla naszych rozważań kluczowe znaczenie posiada prymarny poziom kultury. Zdaniem naszego autora jest on bardzo uschematyzowany. Zawiera \&\#8222;zbiór milczących, domyślnych reguł zachowania i myślenia\&\#8221; [Hall 1999:12]. Składniki te modelują nasze myślenie i spojrzenie na otaczający świat [Hall 2001a :240]. Sprawiają, iż w \&\#8222; niewerbalnej behawioralnej części komunikacji osadzony jest zwykły człowiek i kultura głęboka kierująca jego życiem\&\#8221; [Hall 1999:10].

W przekonaniu Halla kultura poziomu prymarnego wydaje się być bardzo odporna na próby manipulacji z zewnątrz [Hall 1999:13]. Dzięki temu, mimo zmian zachodzących w świecie zewnętrznym, wzorce kulturowego działania nie ulegają przekształceniom i nadal kształtują kulturę. Poznanie tych uwewnętrznionych zasad kulturowych daje klucz do zrozumienia samej kultury i procesów w niej zachodzących. Jednym z takich kluczy jest czas.

\subsection{Czas \&\#8211; bezgłośny język kultury}

Według Halla czas jest głębokim systemem kultury. Stanowi on język i organizator całej ludzkiej aktywności kulturowej. Poprzez czas zyskujemy wgląd w prymarny poziom kultury a jednocześnie kultura pomaga nam w rozumieniu czasu jako systemu kulturowego. Powyższe względy sprawiają, iż zdaniem Halla niemożliwe jest w wielu przypadkach osobne traktowanie czasu i kultury [Hall 1999:9]. Zaproponowany przeze mnie neologizm czaso-kultura ma uzmysławiać nam tego typu sytuacje.

W perspektywie kulturowej czas zdaniem naszego autora stanowi zbitkę różnorodnych koncepcji, wydarzeń i rytmów. Każdy poziom kultury używa przy tym co najmniej kilku rodzajów, możliwych do zdefiniowania, czasów np. świeckiego, sakralnego, fizycznego, metafizycznego, biologicznego, zegarowego itp. [Hall 1999:19-20]. Dla poziomu prymarnego kultury podstawowe znaczenie ma tzw. \&\#8222; czas mikro\&\#8221; [Hall 1999:31]. Według Halla jest to czas specyficzny, stworzony przez ten poziom kultury, unikalny dla każdej z nich, pozostający zupełnie poza zasięgiem świadomości. Cytowany autor twierdzi przy tym, że głównymi odmianami czasu mikro są czas monochroniczny i polichroniczny. Te dwa ostatnie modelują główne wzorce kulturowych zachowań ludzi.

Wzór kulturowy funkcjonujący według czasu monochronicznego [Hall 2001b:25-32] sprawia, iż ludzie realizują swoje zadania w sposób usystematyzowany, \&\#8222; po kolei \&\#8221; według harmonogramu [Hall 1999:55]. Jest to czas linearny; akcentujący plany, segmentacje, dokładność. Czaso-kultura monochroniczna dysponuje czasem jako czymś namacalnym. Stąd odstępstwo od harmonogramu traktowane jest często jako fiasko działań i starta czasu. Zachodzi 
przy tym niebezpieczeństwo, że \&\#8211; jak twierdzi Hall \&\#8211; poprzez swoją precyzję i arbitralność \&\#8222; czas M [monochroniczny \&\#8211; przypis JŁ] może wyobcowywać nas wobec siebie samych i pozbawiać możliwości doświadczenia kontekstu w szerszym sensie. Inaczej mówiąc, czas M zawęża nasz pogląd na zdarzenia [...] i wpływa, subtelnie, lecz gę̧boko, na sposób naszego myślenia, który staje się fragmentaryczny \&\#8221; [Hall 2001b:29]. Według Halla czas monochroniczny wydaje się być typowy dla kultury zachodniej. W moim przekonaniu nie oznacza to jednak, iż lokalne społeczności nie mogą posługiwać się innym, specyficznym wzorcem czaso-kulturowym i tym samym tworzyć własne przedstawienia kultury.

Wzorzec kulturowy tworzony według czasu polichronicznego [Hall 2001b:30-32] preferuje robienie wielu rzeczy jednocześnie. To rodzaj czasu nielinearnego. Czaso-kultura polichroniczna (np. Bliski Wschód, Ameryka Łacińska, Hiszpania) bardziej kładzie nacisk na zaangażowanie człowieka i realizacje (zakończenie) przypisanego mu konkretnego zadania niż na ścisłe trzymanie się rozkładu zajęć. Ludzie kultury czasu polichronicznego nie mają poczucia straconego czasu. Dla nich konkretny moment czasu jest punktem odniesienia \&\#8211; ostatecznym terminem realizacji jakiejś działalności: np. spotkania z przyjaciółmi, skończenia zlecenia, przygotowania transakcji biznesowej itp. Drobiazgowe trzymanie się harmonogramu traktowane jest tu jako pogwałcenie indywidualności jednostki ludzkiej.

Każdy z tych systemów czasowych jest inny; ma swoje silne strony oraz wykazuje rozliczne ograniczenia. Każdy w inny sposób organizuje życie społeczne, system administracyjny, działanie przedsiębiorstw itp. w końcu \&\#8211; co jest $z$ naszego punktu widzenia istotne $\& \# 8211$; tworzy inny rodzaj kultury, która właściwie nie jest już jedynie kulturą lecz konglomeratem czasu i kultury \&\#8211; czaso-kulturą. Śmiem zatem twierdzić, iż uchwycenie czaso-kulturowego wzorca to jeden z podstawowych zabiegów badawczych kultury lokalnej. Poza tym czaso-kultura pozostająca w istocie konglomeratem nie dwóch lecz trzech elementów: przestrzeni (obszar zmysłowej oglądowości, sposób komunikacji kulturowej), czasu (modyfikator przestrzeni, bezgłośny język kultury) i kultury (forma komunikacji międzyludzkiej) determinuje krajobraz kulturowy i jego przemiany.

\subsection{Paradoks: ewolucyjność i stałość krajobrazu kulturowego}

Według Grzegorza Myśliwskiego krajobraz kulturowy to \&\#8222; materialne efekty działalności ludzkiej w środowisku przyrodniczym\&\#8221; [Myśliwski 1999:22] W podobnym duchu definiują tenże krajobraz zarówno Szymański [1983:216-227] jak i Myczkowski. Ten ostatni stwierdza wprost: \&\#8222; krajobraz kulturowy \&\#8211; tradycyjny to obszar o postaci historycznej powstałej 
w wyniku działalności człowieka, którego zewnętrzny wygląd stanowi świadectwo rozwoju cywilizacyjnego w skali krajowej, regionalnej lub lokalnej\&\#8221; [Myczkowski 1998:111]. Zdaniem cytowanego autora krajobraz stanowi równocześnie zewnętrzny i wewnętrzny wyraz tożsamości miejsca i czasu [Myczkowski 1998:24]. Miejsca, które jawi się jako \&\#8222;element strukturalny krajobrazu \&\#8222; uczłowieczonego \&\#8221; bądź przez bezpośredni wpływ działań ludzkich, bądź przez fakt percypowania i w ślad za tym \&\#8211; badania i interpretowania go przez człowieka \&\#8221; [Myczkowski 1998:27].

Owo \&\#8222; uczłowieczanie \&\#8221; przestrzeni, lub \&\#8222; kodowanie w sobie\&\#8221; poprzez krajobraz tożsamości miejsca zdaje się wskazywać kulturę jako konstytutywny składnik krajobrazu kulturowego. W moim przekonaniu krajobraz kulturowy staje się fizjonomią kultury \&\#8211; zewnętrznym przejawem jej składowych: czasowej, przestrzennej i komunikacyjnej. Jako fizjonomia (zmieniającej się w czasie i przestrzeni) kultury sam też ulega zmianie. Jego obecna postać, jest czymś co dziedziczy w sobie zarówno teraźniejszość jak i przeszłość. W tym momencie zaryzykuję następujące twierdzenie: krajobraz kulturowy jest antycypacją przeszłości \&\#8211; poprzez swoje ścisłe związki $\mathrm{z}$ kulturą stanowi zaklętą $\mathrm{w}$ twory materialne, upostaciowioną zbiorową, dziedziczoną przez pokolenia \&\#8222; pamięć \&\#8221; narodu, społeczność, grupy etnicznej itp. Podkreślmy to jeszcze raz krajobraz kulturowy nie jest pamięcią lecz manifestacją pamięci. W takiej perspektywie badawczej nie można mówić o jednym rodzaju krajobrazu kulturowego nawet $\mathrm{w}$ odniesieniu do jednego narodu czy grupy etnicznej ponieważ nie ma jednej pamięci. Każda społeczność ludzka ma swoją historię, swoją kulturę i swoją pamięć wpisaną w pamięć, kulturę czy historię \& \#8222; wyższego poziomu \&\#8221; np. narodu, rasy, cywilizacji etc. Istnieją zatem krajobrazy w krajobrazach. W zależności od skali ujęcia (krajowego, regionalnego czy lokalnego) będziemy mieli do czynienia z różnymi wariantami tego samego krajobrazu kulturowego. Jeden rodzaj krajobrazu zawiera się w drugim. Jeden krajobraz ewoluuje $z$ drugiego. Krajobraz \&\#8222; wyższego poziomu\&\#8221; kształtuje krajobraz na \&\#8222; niższym poziomie \&\#8221.

Ewolucyjność krajobrazu kulturowego nie przekreśla jednak jego zadziwiającej stałości. Pomimo zmieniającej się w przyspieszonym tempie kultury krajobraz kulturowy \&\#8222; reaguje \&\#8221; z pewnym opóźnieniem na zmiany. Jak zauważa Tadeusz Margul w XVI wieku mennonici wypędzani ze Szwajcarii emigrowali do innych krajów. Trafiali do Naderenii, Prus, nad Dniepr, Wołgę, docierali do Uzbekistanu, Kanady, Meksyku i Paragwaju. W nowych miejscach swojego pobytu, pod każdą długością i szerokością geograficzną, pomimo upływu dziesiątków czy nawet setek lat, odtwarzali z uporem swój krajobraz kulturowy [Margul 1998: 130-131]. Również współczesne, nowatorskie w swojej istocie, założenia architektoniczne nadal trzymane są w ryzach poszczególnych wzorców kulturowych. Architekci np. hiszpańscy czy francuscy nadal projektują miasta 
w oparciu o system promienistej gwiazdy. Z kolei np. Amerykanie i Brytyjczycy posługują się wzorcem kratownicy [Hall 2001a:186-187].

Równoczesna ewolucyjność i stałość krajobrazu kulturowego \&\#8211; postrzeganego przeze mnie jako manifestacja zbiorowej \&\#8222; pamięci \&\#8221; narodu, społeczność, grupy etnicznej etc. \&\#8211; prowokuje do postawienia pytania o przyczyny takiego stanu rzeczy. Innymi słowy: dlaczego krajobraz kulturowy lokalnych ojczyzn jest właśnie taki jaki jest? Przecież można wyobrazić sobie inny krajobraz kulturowy dla tej samej społeczności ludzkiej. Odpowiedzi na tak postawiony problem może być wiele. Chcę w tym momencie zaproponować czytelnikowi spojrzenie na powyższą kwestię z perspektywy wysuwanej przez Ruperta Sheldrake \&\#8217;a (kontrowersyjnej, ale prowokującej do polemiki) idei pola morficznego i morficznego rezonansu. Dokładna analiza istoty czy charakteru pola morficznego znacznie wykracza poza ramy niniejszego opracowania \&\#8211; zostanie zatem pominięta. Dla naszych potrzeb skoncentrujemy się jedynie na bardzo skrótowym naszkicowaniu istotnych wątków.

Według Sheldrake \&\#8217; a zarówno morfogeneza, embriogeneza (mające miejsce w obszarze biologii) jak i socjogeneza pozostają pod przyczynowym i formującym wpływem pól morficznych czyli pól organizująco-sprawczych (pól genezy organizacji). Owe pola, będące analogiem fizykalnych pół (grawitacyjnego, elektromagnetycznego itp.), przedstawiają w obszarze świata przyrody podstawowy czynnik formujący zarówno komórki, tkanki, osobniki, populacje jak i całe społeczności (socjalne pole morficzne) [Sheldrake 1994:118]. Podobieństwo do pól fizycznych polega na tym, iż pole morficzne zdolne jest wywoływać fizyczne zmiany choć samo nie jest bezpośrednio obserwowalne [Sheldrake 1981:72]. Obserwować je można pośrednio poprzez efekty jakie sprawia. Innymi słowy pola morficzne stanowią przyczynowy czynnik w rozwoju i utrzymaniu form systemów (kosmicznych, przyrodniczych, społecznych itp.) na wszystkich poziomach złożoności. Istnieje zatem nie jeden rodzaj pola morficznego, ale wiele pól hierarchicznie uorganizowanych poczynając od pierwotnego pola kosmosu poprzez pola behawioralne, społeczne, kulturowe a kończąc na polach gatunkowych, jednostkowych, komórkowych czy krystalicznych.

W przekonaniu Sheldrake \&\#8217; a a-materialne, a-przestrzenne, nie-energetyczne, ewolucyjne w swojej istocie, pole morficzne może być postrzegane również jako nieświadoma, wrodzona pamięć np. gatunku, narodu, rasy etc. Wzmiankowany autor jej źródło [Sheldrake 1988:102] upatruje bądź w platońskim królestwie niezmiennych matematycznych formuł bądź w arystotelesowskiej entelechii \&\#8211; czynniku urzeczywistniającym byt, niematerialnej sile kształtującej celowo materię. Według Sheldrake\&\#8217; a pola morficzne bardziej przypominają entelechie niż niezmienne matematyczne formuly \&\#8211; nie istnieją one na sposób transcendentny, niezależny od np. aktualnych organizmów czy wzorców kulturowych. Pola te oddziałując np. na współczesny model 
kultury same pozostają pod jej wpływem; są zwrotnie kształtowane przez pola dawnych lecz podobnych kultur. Wzmiankowana pamięć, która de facto jest informacją, transmitowaną z pokolenia w pokolenie, na drodze zarówno przekazu genetycznego jak i pozagenetycznego, kształtuje wszystkie bez wyjątku składniki rzeczywistości. Jak zaznaczono wcześniej jej działanie formotwórcze ujawnia się również w sferze społecznej. Pole morficzne czyli pole informacyjne wpływa determinująco zarówno na wzorce indywidualnych zachowań ludzkich jak i na oblicze kultury. Zdaniem Sheldrake \&\#8217; a czynnikiem, który umożliwia tego rodzaju kształtujące działanie jest rezonans morficzny \&\#8211; analog rezonansu energetycznego, elektro-magnetycznego, czy akustycznego \&\#8211; zjawiska wibracji atomów, molekuł, kryształów itp. pobudzanych przez jakiś czynnik fizyczny (np. pole elektromagnetyczne, energie cieplną, uderzenie w strunę etc.). Jego zdaniem podobne zjawisko pobudzania zachodzi w przypadku form czy wzorców organizacji kosmosu. One mogą być aktywowane przez np. pola morficzne. Pola informacyjne nie są bowiem tworami statycznymi lecz dynamicznymi. Pomiędzy dwoma polami morficznymi tworzy się rodzaj oddziaływania-wibracji. Podobnie oddziałują na siebie typowe pola fizykalne. Pod wpływem rezonansu morficznego następuje zarówno transfer nowych informacji jak i stabilizacja dotychczasowej struktury [Sheldrake 1994:121]. Tworzące się wtedy nowe wzory organizacji np. kosmosu czy kultury ulegają ciągłemu powtarzaniu. Poprzez powtarzanie, owe nowe wzory organizacji stają się coraz bardziej zwyczajowe. Z powodu takiego zwyczaju-pamięci tkwiącej w przyrodzie, proces ewolucyjny nabiera cech kumulatywności [Sheldrake 1988:109]. Jak zauważa Sheldrake twórcza (kształtująca) działalność pól nie jest determinowana poprzez pozaczasowe matematyczne prawa, ale przez aktualne formy wzięte np. od wcześniejszych członków gatunku [Sheldrake 1994:110]. Najczęstszy wzór rozwoju jest powtarzany, najbardziej prawdopodobne jest to co będzie ponownie następowało. Pola są sposobami, z racji których zwyczaje, nawyki gatunków, grup etnicznych itp. zostają utrwalane, utrzymywane i dziedziczone. Innymi słowy nowe wzory organizacji dochodzą do istnienia jako zwyczaje przyrody a z racji powtarzania same z kolei stają się zwyczajowe (instynktowne) [Sheldrake 1981:173]. Natura i kultura w takim ujęciu są rodzajem sceny na której działają różnorakie zwyczaje przyrody czy wzorce komunikacji międzyludzkiej \&\#8211; pola organizujące.

Aplikacja tez Sheldrake\&\#8217;a do problemu krajobrazu kulturowego zdaje się tłumaczyć jego równoczesną stałość jak i ewolucyjność. Krajobraz kulturowy ewoluuje ponieważ następuje ciągły transfer nowych informacji w obszarze kultury. Zauważmy przy tym, iż zasymilowane przez kulturę będą tylko te nowe treści, które pozytywnie przejdą przez sito \&\#8222; kulturowej selekcji \&\#8221; \&\#8211; zostaną wielokrotnie powtórzone w kolejnych pokoleniach. Jeśli taki proces nie nastąpi oznacza to, iż nowa idea, odwołująca się nawet do bardzo szczytnych zasad de facto okazała się być mało wiarygodna. 
Równolegle do wzmiankowanego procesu ewoluowania krajobrazu ma miejsce stabilizacja zastałej jego formy. W tym przypadku przekaz pokoleniowy, ciągłe powtarzanie, jeśli nie tych samych to podobnych, wzorców kulturowych konsoliduje społeczną pamięć zbiorowości ludzkiej. Jej manifestacja czyli krajobraz kulturowy będzie bardzo podobny do tego jaki stworzyli nasi przodkowie.

\section{Literatura}

Arystoteles, 1968: Fizyka, przeł. Leśniak K., Warszawa: PWN. Carrel A., Człowiek istota nieznana, przeł. Swietochowski R., Warszawa: Wyd. Biblioteki Wiedzy, (brw). Einstein A., 1958:, Istota teorii względności, przeł. Trautman A., Warszawa: PWN.

Encyklopedia Powszechna PWN, 1984: T: 2, Warszawa: PWN.

Heller M., 1986: Wybrane kierunki i zagadnienia filozofii przyrody, mps., Kraków: PAT. Heller M., Lubański M., Ślaga S.W., 1997: Zagadnienia filozoficzne współczesnej nauki. Wstęp do filozofii przyrody, wyd. 4, Warszawa: ATK. Hall E.T., 1987: Bezgłośny język, przeł. Zimand R., Skarbińska A., Warszawa: PIW.

Hall E.T., 1999: Taniec życia. Inny wymiar czasu, przeł. Nowakowski R., Warszawa: WWL Muza S.A. Hall E.T., 2001a: Ukryty wymiar, przeł. Hołówka T., Warszawa: WWL Muza S.A.

Hall E.T., 2001 b: Poza kulturą, przeł. Goździak E., Warszawa: PWN. Hawking S.W., Penrose R., 1996: Natura czasu i przestrzeni, przeł. Piotr Amsterdamski, Kraków-Poznań: wyd. Zysk i S-ka. Jędrzejczyk D., 2001: Wprowadzenie do geografii humanistycznej, Warszawa: RW UW.

Kant I., 1957: Krytyka czystego rozumu, przeł. R. Ingarden, T:1, Warszawa. Krier L., 2001: Architektura. Wybór czy przeznaczenie, przeł. Choynowski P., Warszawa: Arkady. Liddle A., 2000: Wprowadzenie do kosmologii współczesnej, przeł. Łokas E.L., Bieniok B., Warszawa: Prószyński i S-ka.

Łapiński J., 2002:, Cywilizacyjno kulturowe transformacje przestrzeni społecznej, [w:] Problemy ochrony i kształtowania krajobrazu Górnego Śląska na tle doświadczeń z innych regionów Polski, (red.) Jankowski A.T., Myga-Piątek U., Jankowski G., Sosnowiec, s. 34-40. NorbergSchulz Ch., 2000: Bycie, przestrzeń i architektura, przeł. Gadomska B., Warszawa: Murator. Margul T., 1986: Religia a przestrzeń i krajobraz. Kurs geografii religii dla studentów religioznawstwa i geografii, Kraków: Uniwersytet Jagielloński. Mazierski S., 1961: Filozofia przyrody, mps., Lublin: KUL. Mazierski S., 1972: Elementy kosmologii filozoficznej i przyrodniczej, Poznań-Warszawa Lublin: Księgarnia św. Wojciecha. Myczkowski Z., 1998: Krajobraz wyrazem tożsamości w wybranych obszarach chronionych w Polsce, Kraków: Politechnika Krakowska. Myśliwski G., 1999: Czlowiek średniowiecza wobec czasu i przestrzeni (Mazowsze od XII do poł. XVI wieku), Warszawa: Wydawnictwo Krupski i S-ka. Płachecki M., 1987: Słowo wstępne, [w:] Hall E.T., 1987: Bezgłośny język, przeł. Zimand R., Skarbińska A., Warszawa: PIW, s. 7-18. Sheldrake R., 1981: A New Science of Life. The Hypothesis of Formative Causation, Los Angeles: J.P. Tarcher Inc.

Sheldrake R., 1988: The Presence of the Past. Morphic Resonance and the Habits of Nature, London: Collins. Sheldrake R., 1994: The Rebirth of Nature. The Greening of Science and God, Rochester: Park Street Press. Szymański J., 1983: Nauki pomocnicze historii, Warszawa. Wciórka L., 1993: Filozofia przyrody, Poznań: PWT. 


\title{
Space-time and time-culture. Comments on complementarity of space, culture, time and landscape
}

\begin{abstract}
SUMMARY
It is true to say that there is a wide range of definitions and types of space e.g. abstract space, mathematical space, physical space, social space etc. Cultural depiction of space emphasizes its anthropological dimension. Cultural space is a sphere of social relations, interactions and feed-back between a human being and physical space. According to E.T. Hall, space is a form of communication. In my opinion, it is also the environment for the functioning of culture. Simultaneously, space seems to be a characteristic product of culture. Time is forming the organizations of cultural space. Time is a measure of change (Aristotle) \&\#8211; a total of various rhythms, events and conceptions (E.T. Hall). From an anthropological point of view, time is also a creator of different kinds of space \&\#8211; environments for different kinds of culture. Cultural space and time complement one another. It appears that they should be perceived as space-time. As E.T. Hall claims, culture is a form of interpersonal communication. It is formed by any number of units and it reveals three levels of functioning:

a) conscious, technical;

b) private (or personal);

c) hidden, unconscious, primary.

The essential element shaping all levels of culture \&\#8211; like in case of space \&\#8211; is time (e.g. biological, physical, metaphysical, sacred, cultural etc.) Generally speaking, time is a silent language of culture - one of the basic means of communication. As Hall believes, time is a core system of every culture. As well as being the main organizer of a human being \&\#8217; s cultural activity, time is a tool of insight into culture. In my opinion, cultural research should take the modifying influence of time into consideration. These two factors ought to be treated inseparably as the reality of time-culture. Culture is a constituent of a cultural landscape. In my opinion a cultural landscape is becoming culture $\& \# 8217$; s physiognomy \&\#8211; an external reflection of its constituents: time, space and communication. A cultural landscape is a manifestation of collective national remembrance which was inherited through generations, society and ethnic groups. A cultural landscape evolves within the changes of remembrance, however remains strangely stable. Its changes occur with the delayed reactions. A hypothesis that explains the above characteristic features of a cultural landscape is the one of Rupert Sheldrake \&\#8217; s concept of morphic field and morphic resonance.
\end{abstract}

